\title{
Mean Dosage Stimulation Range of Allelochemicals from Crude Extracts of Cucumis africanus Fruit for Improving Growth of Tomato Plant and Suppressing Meloidogyne incognita Numbers
}

\author{
Osvaldo Pelinganga ${ }^{1} \&$ Phatu Mashela ${ }^{1}$ \\ ${ }^{1}$ School of Agricultural and Environmental Sciences, University of Limpopo, South Africa \\ Correspondence: Phatu Mashela, School of Agricultural and Environmental Sciences, University of Limpopo, \\ South Africa. Tel: 27-152-682-190. E-mail: phatu.mashela@ul.ac.za
}

Received: June 23, 2012 Accepted: August 7, 2012 Online Published: November 15, 2012

doi:10.5539/jas.v4n12p8 URL: http://dx.doi.org/10.5539/jas.v4n12p8

\begin{abstract}
Successful utilisation of allelochemicals in management of plant-parasitic nematodes depends on their degree of phytotoxicity. Conventional methods of determining phytotoxicity are tedious, with inconsistent results. Plants respond to increased dosages of allelochemicals in a density-dependent growth pattern, which allows the use of the Curve-fitting Allelochemical Response Data computer-based model to determine the mean dosage stimulation range of used allelochemicals. The CARD modelling was used to determine the stimulation range of fermented dried crude extracts of wild cucumber (Cucumis africanus) fruit for improving growth of tomato (Solanum lycopersicon) plants, each infested with 1500 eggs and juveniles of the southern root-knot (Meloidogyne incognita) nematode. Dilutions at 0, 2, 4, 8, 16, 32 and 64\% were applied weekly through irrigation system. At 56 days after treatment, CARD demonstrated density-dependent growth patterns as dosages increased. The mean dosage stimulation range of diluted fermented crude extracts, computed from CARD biological indices, was $2.64 \%$ dilution for tomato plant. Since at $2 \%$ dilution, the material reduced final nematode population density of $M$. incognita by $90 \%$. The $2.64 \%$ was suitable for stimulation of tomato plant and suppression of nematode numbers.
\end{abstract}

Keywords: allelochemicals, Cucumis africanus, ground leaching technology, mean dosage stimulation range, Meloidogyne incognita

\section{Introduction}

Increased withdrawal of synthetic chemical nematicides from agrochemical markets exacerbated effects of the root-knot nematodes (Meloidogyne species) in tomato (Solanum lycopersicon) production (Mashela et al., 2011). Worldwide, Meloidogyne species continue to be the most devastating soil-borne pathogen in crop production. Crop losses prior to withdrawal of methyl bromide in 2005 were estimated at US\$125 billion (Chitwood, 2003). In Limpopo Province, South Africa, alternatives to methyl bromide in managing Meloidogyne species focused on uses of allelochemicals from crude extracts of selected plants using the ground leaching technology (GLT) system (Mashela et al., 2011). In this technology, crude extracts are applied in small quantities $(0.2-0.7$ t/ha) into soil around the stem during transplanting and suppressed $M$. incognita from 68-97\% (12). The technology mitigated major drawbacks of conventional organic amendments in management of plant-parasitic nematodes (Stirling, 1991), such as (a) the use of excessively large quantities (10-250 t/ha), thus, reducing transport costs, (b) a waiting period to allow for microbial degradation, and therefore, avoiding negative period, (c) reduction of soil $\mathrm{pH}$ and, therefore, avoiding the unavailability of certain nutrient elements, and (d) inconsistent results on nematode suppression.

Widely used allelochemicals in GLT system include cucurbitacin A [ cucumin $\left(\mathrm{C}_{27} \mathrm{H}_{40} \mathrm{O}_{9}\right)$; leptodermin $\left(\mathrm{C}_{27} \mathrm{H}_{38} \mathrm{O}_{8}\right)$ ] from wild cucumber (Cucumis myriocarpus Naud.) (Jeffrey, 1978; Rimington, 1938) fruit and cucurbitacin B $\left(\mathrm{C}_{32} \mathrm{H}_{48} \mathrm{O}_{8}\right)$ from wild watermelon (Cucumis africanus L. f.) fruit, both being indigenous to South Africa (Mashela et al., 2011). Cucurbitacins A and B are soluble and insoluble in water, respectively (Chen et al., 2005). Two major limiting factors in developing the two cucurbitacins for use in management of plant-parasitic nematodes were that (a) GLT system is labour intensive and, therefore, not cost-effective in large commercial farming systems, (b) the 
two cucurbitacins are highly phytotoxic and (c) conventional methods for determining phytotoxicity in plants are tedious, with inconsistent results (Mashela et al., 2011).

Crude extracts of C. myriocarpus fruit at low dosages suppressed nematode numbers and improved growth of tomato plants (Mashela et al., 2011). Mafeo (2012) observed the existence of density-dependent growth patterns in plant variables as C. myriocarpus fruit dosages increased. Liu et al. (2003) developed the Curve-fitting Allelochemical Response Data (CARD) computer-based model, which quantified density-dependent growth patterns in biological organisms using seven biological indices, among which are those that assist in quantifying the stimulation, saturation and inhibition ranges (Salisbury \& Ross, 1992).

A baseline study was previously conducted using cucurbitacin B through irrigation system in order to ameliorate the cost-ineffectiveness of this material in commercial farming system when used in GLT system (Pelinganga et al., 2012). Cucurbitacin B was extracted by fermenting fresh fruit of $C$. africanus, with a series of dilutions used through irrigation water. At harvest, cucurbitacin B had MDSR of $9 \%$ dilution, which also suppressed $M$. incognita race 2 numbers. However, fresh fruit of $C$. africanus have high incidence of post-harvest decay (Mphahlele et al., 2012), with unavailability challenges in areas where tomatoes are produced all-year-round. Successful use of crude extracts of dried C. africanus fruit in fermented form would mitigate against the unavailability issues. The objective of this study was to use CARD modelling to determine MDSR using dilutions of fermented crude extracts from dried C. africanus fruit for improving growth of tomato plants and suppressing $M$. incognita numbers.

\section{Materials and Methods}

\subsection{Location and Preparation of Materials}

The experiment was conducted at the greenhouse of the Plant Protection Skills Centre, University of Limpopo, South Africa $\left(23^{\circ} 53^{\prime} 10^{\prime \prime} \mathrm{S}, 2^{\circ} 44^{\prime} 15^{\prime \prime} \mathrm{E}\right)$ in spring (August-October) 2011. Ambient day/night temperatures averaged $28 / 21^{\circ} \mathrm{C}$, with maximum temperatures controlled using thermostatically-activated fans. Fruit of Cucumis africanus were harvested from field-grown plants, washed, cut into pieces and dried in air-forced ovens at $52^{\circ} \mathrm{C}$ for $72 \mathrm{~h}$ (Mashela et al., 2011) and ground in a Wiley mill to pass through a 1-mm-opening sieve. Approximately $40 \mathrm{~g}$ of crude extracts per $16 \mathrm{~L}$ tapwater in $20 \mathrm{~L}$ containers were fermented for 14 days at room temperature for $\mathrm{pH}$ to decline from 6.8 to 3.7 (Pelinganga et al., 2012) for preparation of treatment dilutions. When required, nematode inocula were prepared by extracting eggs and second stage juveniles (J2s) of $M$. incognita race 2 from roots of greenhouse-grown nematode-susceptible kenaf (Hibiscus cannabinus L.) in 1\% $\mathrm{NaOCl}$ (Hussey \& Barker, 1973). Twenty-cm-diameter plastic pots, at $0.3 \mathrm{~m}$ inter-row spacing and $0.25 \mathrm{~m}$ intra-row spacing, were each filled with 1 $800 \mathrm{ml}$ steam-pasteurised sand and Hygromix (Hygrotech, Pretoria North, South Africa) at 3:1 (v/v). Uniform four-week-old tomato 'Floradade' seedlings were transplanted and inoculated with 1500 eggs and J2s of $M$. Incognita race 2.

\subsection{Experimental Design and Cultural Practices}

Seven treatments, namely, $0,2,4,8,16,32$ and $64 \%$ dilutions were arranged in a randomised complete block

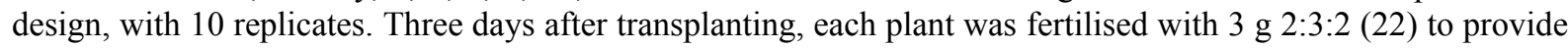
$\mathrm{mg} / \mathrm{ml}$ water of $186 \mathrm{~N}, 126 \mathrm{~K}$ and $156 \mathrm{P}$, with $2 \mathrm{~g} 2: 1: 2$ (43)-providing $0.35 \mathrm{~N}, 0.32 \mathrm{~K}$ and $0.32 \mathrm{P}, 0.9 \mathrm{Mg}, 0.75 \mathrm{Fe}$, $0.075 \mathrm{Cu}, 0.35 \mathrm{Zn}, 1.0 \mathrm{~B}, 3.0 \mathrm{Mn}$ and $0.07 \mathrm{Mo}$. Four sets of Hadeco Moisture Meter (Hadeco, New Delhi, India) were inserted to $10-\mathrm{cm}$ depths in randomly selected pots to monitor soil moisture tension. Plants were irrigated to full capacity using chlorine-free tapwater as soon as $50 \%$ moisture meter readings were below 2 units. Scouting for the greenhouse whitefly (Trialeurodes vaporariorum West.) was done weekly and plants sprayed with $1.33 \mathrm{ml}$ Leybacid (a.i. fenthion 50\% ml)/L water when population densities increased above 10 whiteflies per five randomly selected plants.

\subsection{Data Collection}

Flowers were counted weekly with pedicels marked to avoid recounting. At harvest, 56 days after inoculation, fruit of all sizes were recorded and plant height measured from soil surface to tip of flag leaf. Stems were severed at soil surface and stem diameter measured at $5 \mathrm{~cm}$ above severed ends using a digital vernier caliper. Shoots were oven-dried at $70^{\circ} \mathrm{C}$ for $72 \mathrm{~h}$ for dry shoot mass. Root systems were removed from pots, immersed in water to remove soil particles, blotted dry and weighed to facilitate the calculation of nematode density/total roots/plant. Roots were assessed for galls using the North Carolina differential scale where $0=$ no galls, $1=1-2$ galls, $2=3-10$ galls, $3=11-30$ galls, $4=31-100$ galls and $5=>100$ galls/root system (Taylor $\&$ Sasser, 1978). Nematodes were extracted from total root system/plant by maceration and blending for $30 \mathrm{~s}$ in $1 \% \mathrm{NaOCl}$ (Hussey \& Barker, 1973). The material was passed through nested 61 - and $38-\mu \mathrm{m}$ opening sieves. Contents of the $38-\mu \mathrm{m}$-opening-sieve were 
collected for separation of nematodes from fine debris using the sugar-floatation and centrifugation method (Jenkins, 1964). Soil in each pot was mixed and a $250 \mathrm{ml}$ soil sample collected for nematode extraction using the sugar centrifugation and flotation method (Jenkins, 1964). Eggs and juveniles from root and soil samples were each counted using a stereomicroscope and converted to total root system per plant and total soil per pot, respectively. Root and soil nematodes from samples were converted to final nematode population density ( $\mathrm{Pf}$ ) in root, soil and then the total.

\subsection{Data Analysis}

Data were subjected to analysis of variance (ANOVA) through the 2008 SAS software (SAS Institute, Inc., Cary, NC., USA). Flower, nematode and root gall data were transformed through $\log _{10}(\mathrm{x}+1)$ to homogenise the variances (Gomez \& Gomez, 1984). Sum of squares were partitioned to determine the contribution of sources of variation to the total treatment variation (TTV) in plant and nematode variables (Gomez \& Gomez, 1984). Treatment mean separation was achieved using Waller-Duncan multiple range test at the probability level of 5\% and further subjected to CARD model to generate appropriate biological indices (Liu et al., 2003). Then, after adjusting $R_{h}$ for $D_{m}$ in plant variables, MDSR was computed by halving the sum of $D_{m}$ and adjusted $R_{h}$

Unless otherwise stated, only treatments significant at the probability level of 5\% were discussed.

\section{Results}

\subsection{Effect on Plant Growth}

Treatment effects were significant for dry shoot mass, dry root mass, plant height, stem diameter and nematode numbers. In dry shoot mass, dry root mass, plant height, stem diameter, nematode in roots, nematode in soil and total nematodes the dosage levels contributed $42 \%, 38 \%, 28 \%, 19 \%, 84 \%, 44 \%$ and $82 \%$ to the total treatment variation (TTV), respectively (Table 1). Dosage levels had no effect on numbers of flowers and fruit mass (data not shown).

Plant growth had density-dependent growth patterns as dosage levels increased (Figure 1). Biological indices in CARD model were strongly explained by dosage levels as shown by coefficients of variation $\left(\mathrm{R}^{2}\right)$ of dry shoot mass, dry root mass, plant height and stem diameter at $96 \%, 97 \%, 99 \%$ and $90 \%$, respectively (Table 2). Various plant organs had different biological indices except for $\mathrm{k}$ values, which were for each organ equivalent to unity. Overall, MDSR dilution of fermented crude extracts of C. africanus fruit for tomato was at 2.64\%.

\subsection{Effect on Nematode Suppression}

Relative to untreated control, dosages of crude extracts from $C$. africanus fruit reduced nematode numbers from $85-97 \%, 45-96 \%$ and $78-97 \%$ for root, soil and total nematodes, respectively (Table 3). The impact of dilutions appeared to be inversely proportional to the dosage level in all measurement units. In untreated control, galling was higher than in treated plots, while the latter were not different from one another.

\section{Discussion}

\subsection{Plant Growth}

High coefficients of determination $\left(\mathrm{R}^{2}\right)$ for CARD models in four plant variables suggested strong density-dependent relationships between growth of tomato and increasing dilutions of crude extracts of $C$. africanus fruit. Generally, $\mathrm{k}$ values of unity in all organs suggested that in tomato plant, the assessed organs had similar sensitivities to dilutions of allelochemicals from fermented crude extracts of $C$. africanus fruit. Plant sensitivity is indirectly proportional to $\mathrm{k}$ values, with zero suggesting the highest sensitivity to allelochemicals used, while high $\mathrm{k}$ values suggested decreased sensitivities (Liu et al., 2003). Observed $\mathrm{k}$ values on tomato in this study were different from zero values observed for dry shoot mass, plant height and stem diameter under dilutions from fresh fermented C. africanus fruit (Pelinganga et al., 2012). In GLT, Mafeo (2012) showed that k values of tomato seedlings ranged from 9 to 20 depending on the investigated organ. Apparently, k values are affected by various factors, which may include fermentation of dried versus fresh materials, fermented versus unfermented, age of the test plant and/or organ of the test plant.

Overall, $\Sigma \mathrm{k}$ value for whole tomato plant in the current study was 4 , while that for fresh fermented fruit of $C$. africanus was unity (Pelinganga et al., 2012), which is another cue suggesting that fermented fresh fruit of $C$. africanus are more phytotoxic to tomato plants than fermented dried fruit. Grinding concentrates potent chemicals which are responsible for stimulation of plant growth at low levels. However, our results cannot be compared with those of Mafeo (2012) since plants were exposed to unfermented crude extracts for 18 days, while in this and other studies (Pelinganga et al., 2012) exposure time was for 56 days. Thus, proper trials using dry and equivalent fresh 
materials are required to make reliable inferences about the sensitivity (k) of crops to fermented crude extracts of Cucumis fruits.

Stimulation of plant growth at low dosages of crude extracts of Cucumis fruits appears to be universal, as shown in various organisms using various types of allelochemicals (Liu et al., 2003). The phenomenon was previously observed in eight and ten monocotyledonous and dicotyledonous plants, respectively (Mafeo, 2012). Certain cucurbitacins from Cucumis fruits were shown to have anticancer activities at high dosages, which however, had nonspecific cytotoxicity, while at low dosages the materials stimulated cell division (Chen et al., 2005; Geissman, 1964). MDSR of $2.64 \%$ from fermented crude extracts in this study is much lower than that derived from fermented fresh fruit of C. africanus, which was approximately 9\% (Pelinganga et al., 2012). The disparities in MDSR from dried and fresh materials could explain why fermented fresh fruit of C. africanus in Pelinganga et al. (2012) had much lower $\mathrm{k}$ values than those of fermented dried fruit in the current study. The recommended MDSR is much lower than $\mathrm{D}_{0}$ and $\mathrm{D}_{50}$ inhibition biological indices, which, in this study were $9.76 \%$ and $1181.71 \%$, respectively. Thus, the MDSR also ensures that a phytotoxic dosage level is not incorrectly recommended.

\subsection{Nematode Suppression}

Suppression of nematodes in all test dosages confirmed the nematicidal properties of allelochemicals in $C$. africanus (Mashela et al., 2011). Observed nematode suppression in both root and soil were quite high. The decline in the efficacy of the dilutions in nematode suppression could also be attributed to the phytotoxicity of the materials, which inadvertently affect infection sites and therefore, nematode numbers. Nematode suppression using fermented crude extracts in our study was comparable to that observed when using fermented fresh fruit of $C$. africanus (Pelinganga et al., 2012). Apparently, drying at $52^{\circ} \mathrm{C}$ for $72 \mathrm{~h}$ had no effect on cucurbitacin $\mathrm{B}$, which had been identified as a potent allelochemical that confers nematicidal properties in crude extracts from $C$. africanus fruit.

\section{Conclusion}

In dried form, MDSR from fermented crude extracts of $C$. africanus fruit was established for tomato plants and suppression of $M$. incognita race 2 population densities. The derived MDSR should, accordingly be validated under various environmental conditions using different tomato cultivars. Successful validation would enable the cultivation of C. africanus in summer and process the crude extracts from fruit and then store the materials in dried form for use during off-seasons.

\section{Acknowledgements}

The authors are indebted to the Department of Science and Technology, the Land Bank Chair of Agriculture-University of Limpopo, Department of Science and Technology and the Flemish Interuniversity Council (VLIR) for providing financial support.

\section{References}

Chen, J. C., Chiu, M. H., Nie, R. L., Cordell, G. A., \& Qiu, S. X. (2005). Cucurbutacins and Cucurbitane glycosides: Structures and biological activities. Natural Products Reproduction, 22, 386-399. http://dx.doi.org/10.1039/b418841c

Chitwood, D. J. (2003). Research on plant-parasitic nematode biology conducted by the United States Department of Agricultural Research Services. Pest Management Science, 59, 748-753. http://dx.doi.org/10.1002/ps.684

Geissman, T. A. (1964). New substances of plant origin. Annual Review of Pharmacology, 4, 305-316. http://dx.doi.org/10.1146/annurev.pa.04.040164.001513

Gomez, K. A., \& Gomez, A. A. (1984). Statistical procedures for agricultural research. 1st Edition. New York: Wiley.

Hussey, R. S., \& Barker, K. R. (1973). A comparison of methods of collecting inoculants Meloidogyne species including a new technique. Plant Disease Report, 57, 1025-1028.

Jeffrey, C. (1978). Cucurbitaceae. In E. Launert (Ed.), Flora Zambesiac. United Kingdom: Managing Committee.

Jenkins, W. R. (1964). A rapid centrifugal-floatation technique for separating nematodes from soil. Plant Disease Report, 48, 692.

Liu, D. L., An, M., Johnson, I. R., \& Lovett, J. V. (2003). Mathematical modeling of allellopathy. III. A model for curve-fitting allellochemical dose responses. Non-linearity Biology, Toxicology and Medicine, 1, 37-50. http://dx.doi.org/10.1080/15401420390844456 
Mafeo, T. P. (2012). Responses of economically important crops to crude extracts of Cucumis fruit when used as pre-emergent bio-nematicide. $\mathrm{PhD}$ Thesis submitted to the University of Limpopo, Sovenga, South Africa.

Mashela, P. W., De Waele, D., \& Pofu, K. M. (2011). Use of indigenous Cucumis technologies as alternative to synthetic nematicides in management of root-knot nematodes in low-input agricultural farming systems: A Review. Scientific Research Essay, 6, 6762-6768.

Mphahlele, R. R., Mashela, P. W., \& Pofu, K. M. (2012). Post-harvest fruit decay-inducing pathogen in medicinally important Cucumis species indigenous to South Africa. African Journal of Agricultural Research, 6, 3786-3791.

Pelinganga, O. M., Mashela, P. W., Nzanza, B., \& Mphosi, M. S. (2012). Baseline information on using fermented crude extracts from Cucumis africanus fruit for suppression of Meloidogyne incognita and improving growth of tomato plant. African Journal of Biotechnology, 11, 11407-11413.

Rimington, P. (1938). Medicinal and poisonous plants of South and East Africa. Pietermaritzburg: University of Natal Press.

Salisbury, F. B., \& Ross, C. W. (1992), Plant physiology. 4th Edition. Belmont, USA: Wadsworth.

Stirling, G. R. (1991). Biological control of plant parasitic nematodes: Problems progress and prospects. Wallingford: CAB international.

Taylor, A. L., \& Sasser, J. N. (1978). Biology, identification and control of root-knot nematodes (Meloidogyne species). Raleigh, North Carolina: North Carolina State University Press. 